\title{
The changing frequency of celiac disease diagnosed at the Stollery Children's Hospital
}

\author{
Seema Rajani, Hien Q Huynh MD, Justine Turner MD PhD
}

\begin{abstract}
S Rajani, HQ Huynh, J Turner. The changing frequency of celiac disease diagnosed at the Stollery Children's Hospital. Can J Gastroenterol 2010;24(2):109-112.
\end{abstract}

BACKGROUND: Celiac disease (CD) is recognized as one of the most common and important autoimmune gastrointestinal disorders affecting children. There is evidence that a diagnosis of CD during childhood improves health outcomes. The increasing prevalence of $\mathrm{CD}$ is due to increased awareness of the wide range of extraintestinal symptoms associated with CD.

OBJECTIVE: To determine whether there has been a temporal increase in the diagnosis of $\mathrm{CD}$ associated with an increased diagnosis of children without typical gastrointestinal symptoms at the Stollery Children's Hospital (Edmonton, Alberta).

METHODS: Patients with biopsy-proven CD diagnosed at the Stollery Children's Hospital from 1998 to 2007, were identified by retrospective chart review. Baseline and follow-up data, including demographics, symptoms, risk factors, anthropometrics and laboratory investigations, were collected

RESULTS: An increase in the frequency of diagnosis of CD was noted during the study period, particularly from January 2003 onward. Before January 2003, nine children were diagnosed with CD - all with typical symptoms. Between January 2003 and January 2007, inclusive, 149 children were diagnosed with CD, of whom $46 \%$ had absent or atypical symptoms. At follow-up, $96 \%$ of patients reported improved symptoms, including $53 \%$ of individuals who reported being asymptomatic before diagnosis.

CONCLUSIONS: In the last four years of the period studied, the number of children diagnosed with CD at Stollery Children's Hospital increased 11-fold. Screening children at risk for CD, and those with atypical presentations, contributed to the increased number of diagnoses. Identification of CD and establishment of lifelong, dietary gluten avoidance during childhood has important health benefits and should be encouraged.

Key Words: Asymptomatic; Atypical symptoms; Celiac disease; Children; Diagnosis

$\mathrm{C}$ eliac disease (CD) is a common autoimmune disorder triggered by ingestion of the gluten protein that causes damage to the small intestinal mucosa, leading to malabsorption and gastrointestinal complications (1). The only effective treatment is the total elimination of foods containing gluten for the patient's entire life. Although it is common, CD may present without symptoms or with atypical symptoms, making the diagnosis difficult.

The 'iceberg' model has been used to describe the expected prevalence of CD (2). The tip of the iceberg represents patients who present with typical symptoms. The submerged part of the

\section{Fréquence changeante de la maladie coliaque diagnostiquée au Stollery Children's Hospital}

HISTORIQUE : La maladie coliaque (MC) est reconnue comme une maladie intestinale auto-immune répandue et majeure chez l'enfant. On sait que le diagnostic de MC posé durant l'enfance améliore le pronostic. La prévalence croissante de la MC est due au fait qu'on reconnaît davantage les divers symptômes extra-intestinaux qui y sont associés.

OBJECTIFS : Déterminer si le nombre de diagnostics de $\mathrm{MC}$ a augmenté avec le temps en lien avec la hausse du nombre de diagnostics posés chez des enfants n'en manifestant pas les symptômes gastrointestinaux typiques au Stollery Children's Hospital (Edmonton, Alberta).

MÉTHODES : Un examen rétrospectif des dossiers a permis de recenser les diagnostics de MC, biopsie à l'appui, au Stollery Children's Hospital, entre 1998 et 2007. Les auteurs ont recueilli les données de départ et de suivi, dont les caractéristiques démographiques, les symptômes, les facteurs de risque, les données anthropométriques et les résultats d'analyses de laboratoire.

RÉSULTATS : On a noté une augmentation de la fréquence des diagnostics de $\mathrm{MC}$ durant la période de l'étude, particulièrement à partir de janvier 2003. Avant janvier 2003, neuf enfants avaient reçu un diagnostic de $\mathrm{MC}$ et présentaient tous des symptômes typiques. Entre janvier 2003 et janvier 2007, inclusivement, un diagnostic de MC a été posé chez 149 enfants, dont $46 \%$ présentaient des symptômes légers ou atypiques. Au moment du suivi, $96 \%$ des patients ont fait état d'une amélioration de leurs symptômes, dont 53 \% disaient n'éprouver aucun symptôme au moment du diagnostic.

CONCLUSIONS : Au cours des quatre dernières années de la période de l'étude, on a dénombré onze fois plus d'enfants ayant reçu un diagnostic de MC au Stollery Children's Hospital. Le dépistage de la MC chez les enfants à risque et les enfants présentant des tableaux atypiques a contribuéà faire augmenter le nombre de diagnostics. La reconnaissance de la $\mathrm{MC}$ et la mise en place d'un régime sans gluten à vie dès l'enfance offrent de nombreux avantages pour la santé et sont à promouvoir.

iceberg represents patients who remain undiagnosed because they exhibit atypical and/or silent symptoms. The atypical patients usually present with short stature, osteoporosis or anemia, while asymptomatic patients present, on the basis of screening at-risk populations, without symptoms or with lowintensity symptoms such as fatigue, irritability and depression (1). For every diagnosis of $\mathrm{CD}$, five to 10 cases remain undiagnosed (1). It is imperative to diagnose CD and close this gap because although patients may appear to be asymptomatic, they can experience the same long-term risks as symptomatic patients (3).

Division of Gastroenterology and Nutrition, Department of Pediatrics, University of Alberta, Edmonton, Alberta

Correspondence and reprints: Dr Justine Turner, Department of Pediatric Gastroenterology and Nutrition, University of Alberta and Stollery

Children's Hospital, 8440-112 Street, Edmonton, Alberta T6G 2PJ. Telephone 780-407-3339, fax 780-407-3507,

e-mail justine.turner@capitalhealth.ca

Received for publication February 10, 2009. Accepted April 22, 2009 


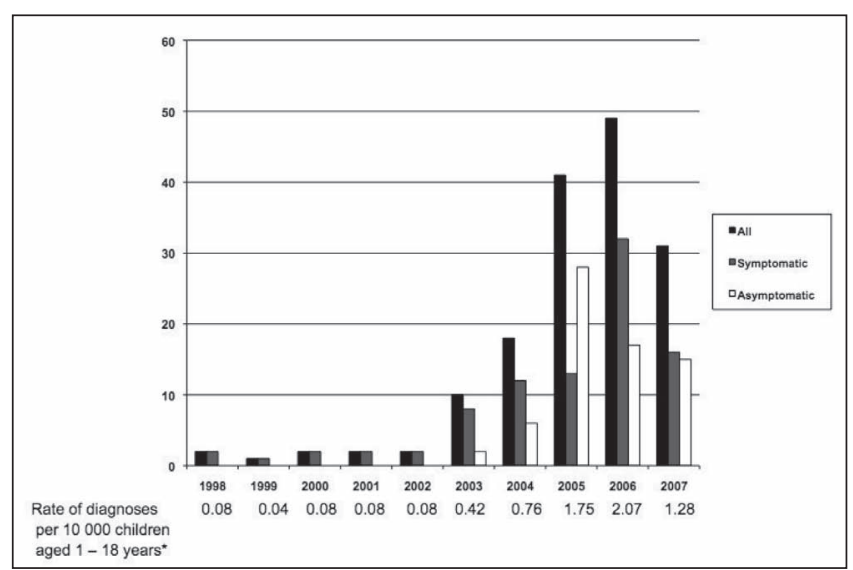

Figure 1) Children diagnosed with celiac disease from 1998 to 2007 at the Stollery Children's Hospital (Edmonton, Alberta). *Data from the Alberta Health Care Insurance Plan registration file

TABLE 1

Anthropometric and demographic data for symptomatic and asymptomatic patients at diagnosis

\begin{tabular}{|c|c|c|}
\hline & \multicolumn{2}{|c|}{ Patients } \\
\hline & $\begin{array}{c}\text { Symptomatic } \\
(n=105)\end{array}$ & $\begin{array}{c}\text { Asymptomatic } \\
(n=53)\end{array}$ \\
\hline Age at diagnosis, years & $8.8 \pm 3.9$ & $9.6 \pm 4.2$ \\
\hline ATTG, U/mL & $274 \pm 514$ & $312 \pm 905$ \\
\hline Height Z score & $-0.16 \pm 1.2$ & $0.30 \pm 1.1^{*}$ \\
\hline Height $Z$ score $\leq-2, \%$ & 7 & 0 \\
\hline Weight Z score & $-0.21 \pm 1.8$ & $0.66 \pm 1.3^{\star \star}$ \\
\hline Weight $Z$ score $\leq-2, \%$ & 10 & 0 \\
\hline Bone density $Z$ score $^{\dagger}$ & $-0.98 \pm 1.1$ & $-0.88 \pm 0.9$ \\
\hline Bone density $Z$ score $\leq-2, \%$ & 17 & 13 \\
\hline
\end{tabular}

Data presented as mean $\pm S D$ unless indicated otherwise. ${ }^{*} P<0.05$; ${ }^{* *} P<0.005$; 'Symptomatic ( $\left.n=96\right)$, asymptomatic $(n=47)$. ATTG Antitissue transglutaminase antibody

According to the North American Society for Pediatric Gastroenterology, Hepatology and Nutrition (4), screening high-risk groups, including patients with type 1 diabetes, a family history of CD, Down syndrome, dermatitis herpetiformis and immunoglobulin A deficiency, is warranted. The present study was undertaken to determine whether the prevalence of CD had increased over time at the Stollery Children's Hospital (Edmonton, Alberta), due to increased screening of high-risk groups.

\section{METHODS}

A retrospective review of the clinical charts of $\mathrm{CD}$ patients dating from 1998 to 2007, diagnosed at Stollery Children's Hospital was performed to obtain data such as demographics, symptoms, risk factors, anthropometrics and laboratory investigations, including serum antitissue transglutaminase antibodies (ATTG) and dual-energy $\mathrm{x}$-ray absorptiometry bone density scans. Stollery Children's Hospital is the only tertiary pediatric referral centre for children in northern Alberta. This was the only referral centre for pediatric gastroenterology services during the interval that the study examined, and the Division of Pediatric Gastroenterology and Nutrition maintained a database of pediatric patients diagnosed with $\mathrm{CD}$ at endoscopy. Only patients
TABLE 2

Anthropometric and demographic data for symptomatic and asymptomatic patients at follow-up

\begin{tabular}{lcc}
\hline & \multicolumn{2}{c}{ Patients } \\
\cline { 2 - 3 } & $\begin{array}{c}\text { Symptomatic } \\
(\mathbf{n}=98)\end{array}$ & $\begin{array}{c}\text { Asymptomatic } \\
(\mathbf{n}=\mathbf{3 5})\end{array}$ \\
\hline Time from diagnosis, months & $6.3 \pm 3.9$ & $7.0 \pm 2.8$ \\
Age at diagnosis, years & $9.4 \pm 4.0$ & $10.1 \pm 4.3$ \\
ATTG, U/mL & $9.4 \pm 14.4$ & $10.0 \pm 8.4$ \\
Height Z score & $-0.04 \pm 1.2$ & $0.10 \pm 1.0$ \\
Height Z score $\leq-2, \%$ & 5 & 0 \\
Weight Z score & $0.03 \pm 1.2$ & $0.66 \pm 1.4^{*}$ \\
Weight Z score $\leq-2, \%$ & 5 & 0 \\
Feel health improved, \% & 96 & 53 \\
\hline
\end{tabular}

Data presented as mean $\pm S D$ unless indicated otherwise; ${ }^{*} P<0.05$. ATTG Antitissue transglutaminase antibody;

who were on a gluten-containing diet, were biopsy-positive for CD and underwent endoscopy at Stollery Children's Hospital, were included in the present review. All biopsies were reviewed by an experienced pathologist and confirmation of a Marsh II or III lesion was required for a diagnosis of CD (5). Patient anthropometrics were standardized using SD or Z scores for weight and height compared with age-matched controls using Epi Info version 3.4.3, downloaded from the Centres for Disease Control and Prevention Web site (www.cdc.gov/epiinfo/). Spine bone mineral density (BMD) was also normalized for age and sex by the use of $\mathrm{Z}$ scores according to the dualenergy x-ray absorptiometry manufacturer's (QDR 4500C, Hologic, USA) normative data.

\section{RESULTS}

Figure 1 illustrates the marked increase in the number of patients diagnosed with CD from 1998 to 2007, including the rate standardized per 10,000 children one to 18 years of age in the health region. It was evident that the increase was particularly marked from 2003 to 2007, when asymptomatic and atypical presentations were included among those being diagnosed. In total, 158 pediatric patients were diagnosed with $\mathrm{CD}$ at the Stollery Children's Hospital. Ninety-six patients had typical symptoms, including abdominal pain, diarrhea and failure to thrive. Nine patients presented with atypical symptoms such as iron deficiency, headaches, tremors, fatigue, constipation and rectal prolapse. Fifty-three of the patients diagnosed with $\mathrm{CD}$ were asymptomatic at presentation and screened for risk factors alone. Risk factors for screening included type 1 diabetes, a family history of $\mathrm{CD}$, Down syndrome, dermatitis herpetiformis, immunoglobulin A deficiency and obesity with borderline hypothyroidism. The majority of patients for whom screening was indicated were asymptomatic (53 of 73) and most were screened for a family history of CD (26 of 53).

Data for asymptomatic and symptomatic patients are summarized in Table 1. From the anthropometric data, the heights and weights of patients were generally in the normal range. However, mean weight and height $\mathrm{Z}$ scores were lower in symptomatic patients who, more often, had a weight and height $\mathrm{Z}$ score of less than or equal to -2 .

As shown in Table 2, the first follow-up appointment for children after a diagnosis of $\mathrm{CD}$ and on a gluten-free diet (GFD) was at approximately six months. Although the ATTG levels 


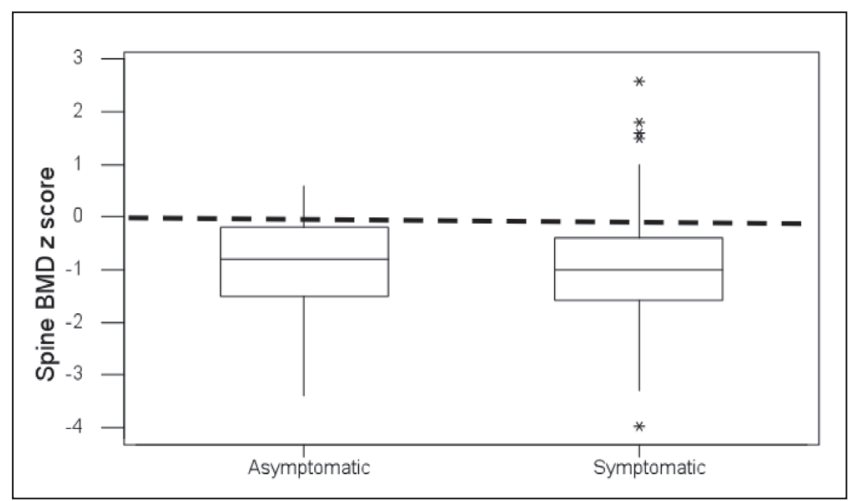

Figure 2) Dual x-ray absorptiometry box plots. Spinal bone mineral density (BMD) Z scores for symptomatic and asymptomatic patients at presentation. *Statistical outliers.

of patients who commenced a GFD were still slightly above normal, they had dramatically decreased. In addition, the height and weight $\mathrm{Z}$ scores remained normal. Ninety-six per cent of symptomatic patients reported feeling better (defined as a partial or complete resolution of their symptoms) while on a GFD. Furthermore, 53\% of asymptomatic patients reported an improvement in their health, usually described in terms of more energy, less irritability and less fatigue.

Figure 2 shows that the mean patient spine BMD was approximately one SD below the normal mean for age and sex, and was similar between symptomatic and asymptomatic children at diagnosis. The change in anthropometrics of 40 patients who were followed to one year and had spine BMD measured at diagnosis and at follow-up was investigated (Figure 3). The patients' heights and weights remained relatively normal, with mean values approaching a $\mathrm{Z}$ score of $\mathrm{O}$. However, the $\mathrm{BMD}$ of this group of patients was approximately two SDs below normal at the time of diagnosis, with a slight but not statistically significant increase noted at follow-up.

\section{DISCUSSION}

The epidemiology of CD has changed dramatically over the past 20 years. Recognition of the myriad clinical presentations of this autoimmune disorder and the need to screen for CD in the presence of risk factors has led to an increased prevalence reported in North America, from one in 10,000 in 1994 to one in 111 individuals in 2000 (1) - an astounding difference! In addition, there has been a shift upward in the age of CD diagnosis (6). While the classical presentation of CD was a readily identifiable child younger than two years of age, with flat buttocks, a protuberant abdomen and muscle wasting, this is no longer the contemporary presentation.

$\mathrm{CD}$ is common, and without treatment confers significant morbidity and risk of mortality. CD patients have two times the mortality rate of the general population (7). However, after implementing a GFD, CD patients may decrease their mortality to levels comparable with the general population. The longer a patient is exposed to gluten, the higher the risk of being affected by gastrointestinal malignancy, osteoporosis and other autoimmune disorders (8-10). Early diagnosis of CD in childhood allows for an early start to a GFD, leading to a higher likelihood of compliance as well as decreasing the risk of future complications such as osteoporosis. Indeed, accrual of

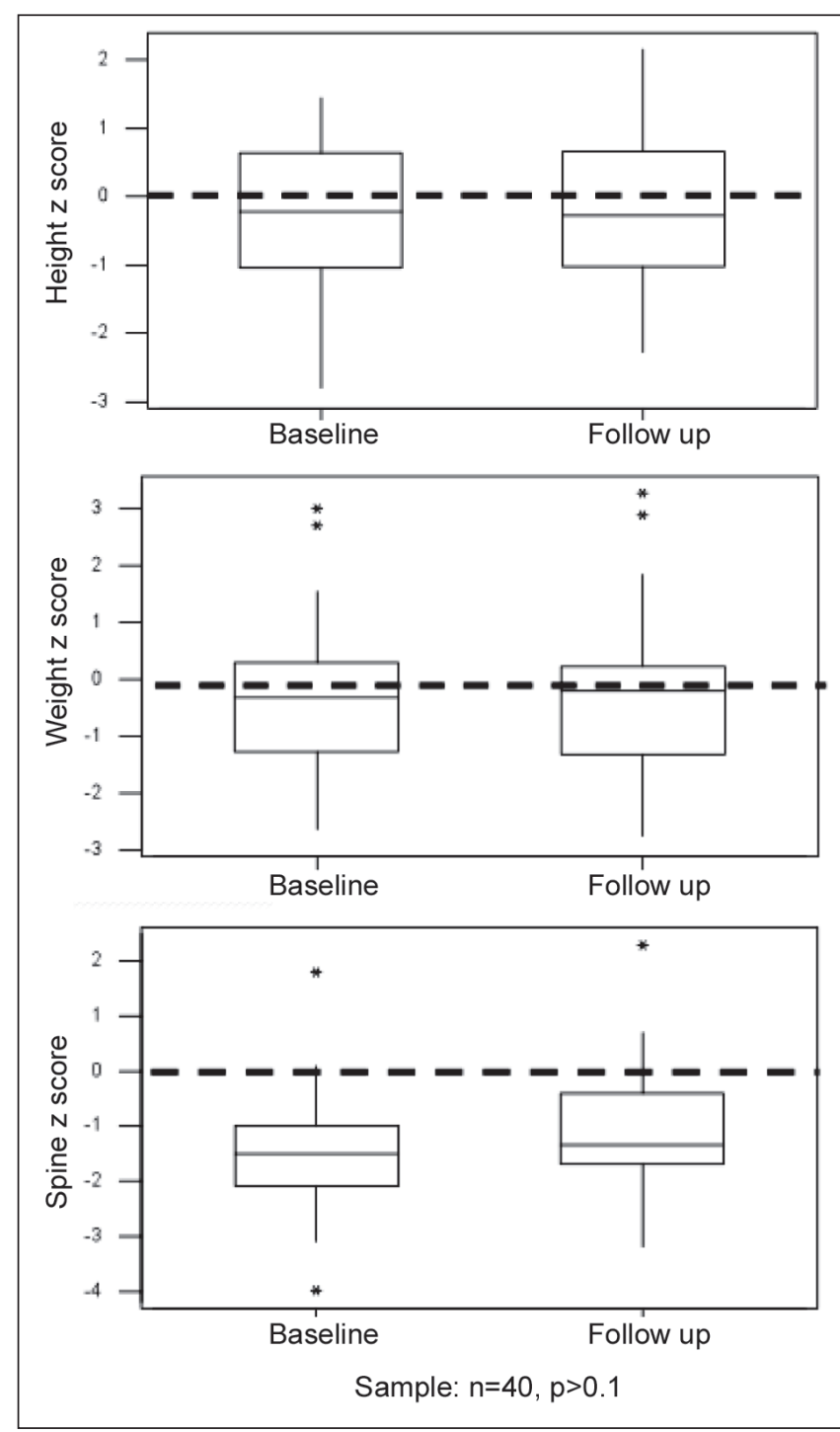

Figure 3) Change in anthropometric $Z$ scores (height, weight and bone mineral density) of 40 patients at baseline and at one-year follow-up. * Statistical outliers. P>0.1 applies only to the spinal Z score

bone mass is a critical issue for growing children and compliance with a GFD is associated with normalizing bone mass in children, but less clearly so for adults diagnosed with CD $(11,12)$. In addition, quality of life may be improved by early diagnosis of CD (13). Importantly, these statements appear to apply equally to patients with or without symptoms at diagnosis $(14,15)$. In this regard, our findings of similarly decreased bone mass in young children at diagnosis of $\mathrm{CD}$, independent of symptomology, and of self-reported improvement in sense of well being, even in children who were initially asymptomatic, are noteworthy.

Our study shows a dramatic increase in the frequency of diagnosis of CD at Stollery Children's Hospital over the nine years studied. Although it is possible that some children with CD were diagnosed elsewhere in northern Alberta during the time of the present study, it is likely a very small number and would not be expected to change the significant temporal trend. The increase in diagnoses over time is related to an 
increase in the screening of high-risk groups. By increasing awareness of the myriad presentations of $\mathrm{CD}$, including screening of high-risk groups, we can make an early diagnosis and implement appropriate treatment to decrease complications. This is important to decrease both childhood morbidity and late complications, and because long-term compliance with a GFD may be improved by early diagnosis.

Another factor accounting for the increased prevalence of $\mathrm{CD}$ may be the recent availability of high-quality and costeffective screening tools. The introduction of the ATTG blood test, 10 to 15 years previously, has allowed family physicians and pediatricians to more accurately screen their patients before referring them to a gastroenterologist. Another contributing factor would be the increase in the local population of Northern Alberta. Although the population of children one to 18 years of age in the health region of interest increased steadily from 234,825 in 1998 , to 241,506 in 2007 , it is unlikely to have accounted for the dramatic rise in $C D$ diagnoses observed.

Our study has demonstrated the importance of diagnosing CD. It is a chronic disease that affects patients' nutrition, bone mass and overall health. It is especially important to diagnose individuals during childhood. Importantly, both asymptomatic and symptomatic patients experience an improvement in their

\section{REFERENCES}

1. Green PHR, Cellier C. Celiac disease. N Engl J Med 2007;357:1731-40.

2. Fasano A, Catassi C. Current approaches to diagnosis and treatment of celiac disease: An evolving spectrum. Gastroenterology 2001;120:636-51.

3. Goddard CJR, Gillet HR. Complications of coeliac disease: Are all patients at risk? Postgrad Med J 2006;82:702-12.

4. Hill ID, Dirks MH, Liptak GS, et al. Guideline for the diagnosis and treatment of celiac disease in children: Recommendations of the North American Society for Pediatric Gastroenterology, Hepatology and Nutrition. J Pediatr Gastroenterol Nutr 2005;40:1-19.

5. Marsh MN. Gluten, major histocompatibility complex, and the small intestine. A molecular and immunobiologic approach to the spectrum of gluten sensitivity (celiac sprue). Gastroenterology 1992;102:330-54.

6. Garampazzi A, Rapa A, Mura S, et al. Clinical pattern of celiac disease is still changing. J Pediatr Gastroenterol Nutr 2007;45:611-4.

7. Corrao G, Corazza GR, Bagnardi V, et al. Mortality in patients with coeliac disease and their relatives: A cohort study. Lancet 2001;358:356-61.

8. Silano M, Volta U, Mecchia AM, et al. Delayed diagnosis of coeliac disease increases cancer risk. BMC Gastroenterology 2007;7:8. overall well being. In addition, most of our patients' symptoms were completely resolved, while the asymptomatic patients noted a meaningful improvement. Nevertheless, the identification of $\mathrm{CD}$ in the population clearly requires further improvement because we continue to diagnose symptomatic patients at twice the rate of asymptomatic patients.

A new factor that will impact the diagnosis of $C D$ in our communities is the availability of the over-the-counter 'Biocard Celiac Test' (ANI Biotech, Finland) - a home ATTG test kit for CD. This fingertip blood sample test provides a screening result for $\mathrm{CD}$ within $10 \mathrm{~min}$. This will lead to an increased awareness and diagnosis of CD that will call for more resources to be made available. In particular, resources will need to be allocated to the education of families and doctors on the need to confirm a diagnosis of $\mathrm{CD}$ with a small bowel biopsy before commencing a GFD. Timely access to a small bowel biopsy will be a major factor in ensuring an accurate diagnosis of CD.

The ease and availability of screening tools for $\mathrm{CD}$, along with the rising awareness of silent and atypical symptoms of this disease, will result in a greater portion of the population constituting the submerged part of the 'iceberg' being diagnosed. As we start chipping at the iceberg, we will need to have the resources in hand to manage the increasing prevalence of CD.

9. Kavak US, Yuce A, Kocak N, et al. Bone mineral density in children with untreated and treated celiac disease. J Pediatr Gastroenterol Nutr 2003;37:434-6.

10. Ventura A, Maguzzu G, Greco L. Duration of exposure to gluten and risk for autoimmune disorders in patients with celiac disease. Gastroenterology 1999;117:297-303.

11. Valdimarsson T, Toss G, Lofman O, Strom M. Three years' follow-up of bone density in adult coeliac disease: Significance of secondary hyperparathyroidism. Scand J Gastroenterol 2000;35:274-80.

12. Mora S, Barera G, Beccio S, et al. Bone density and bone metabolism are normal after long-term gluten-free diet in young celiac patients. Am J Gastroenterol 1999;94:398-403.

13. Matti A, Verkasalo O, Raitakari J, et al. Undiagnosed silent coeliac disease: A risk for underachievement? Scand J Gastroenterol 2005; $40: 1407-12$.

14. Szathmari M, Tulassay T, Arato A, et al. Bone mineral content and density in asymptomatic children with coeliac disease on a gluten free diet. Eur J Gastroenterol Hepatol 2001;13:419-24.

15. Viljamaa M, Collin P, Huhtala $\mathrm{H}$, et al. Is coeliac disease screening in risk groups justified? A fourteen-year follow up with special focus on compliance and quality of life. Aliment Pharmacol Ther 2005;22:317-24. 


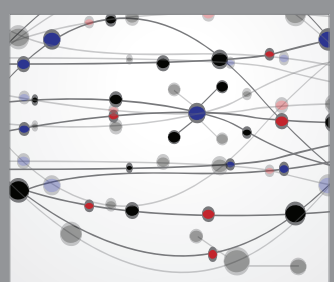

The Scientific World Journal
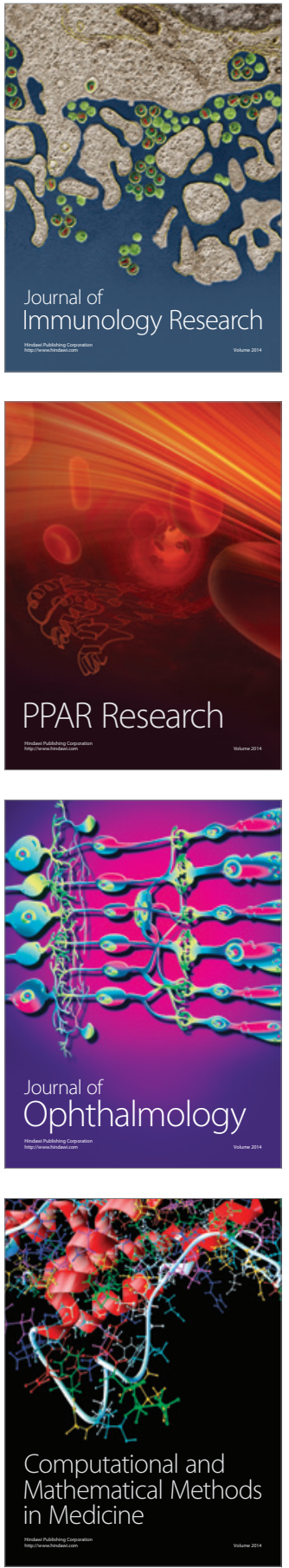

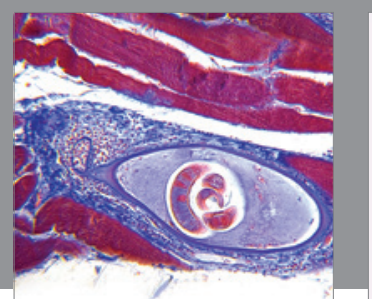

Gastroenterology Research and Practice

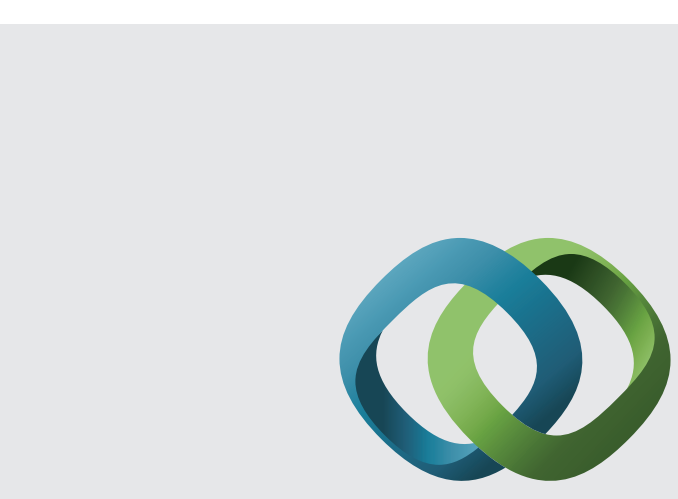

\section{Hindawi}

Submit your manuscripts at

http://www.hindawi.com
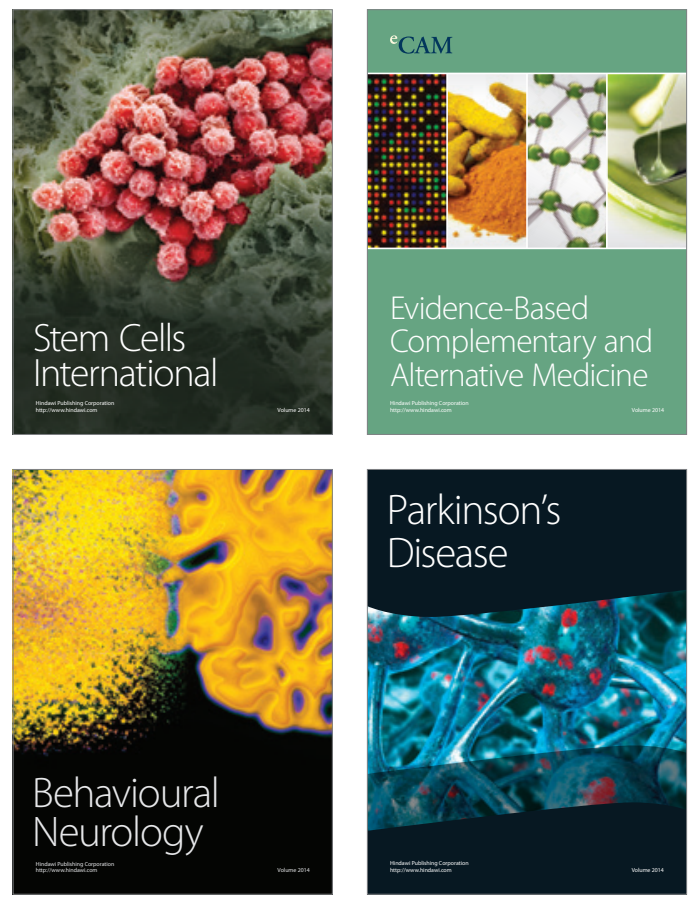
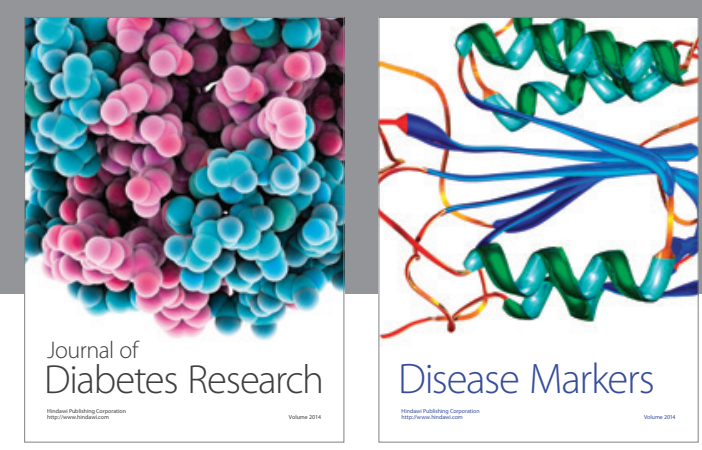

Disease Markers
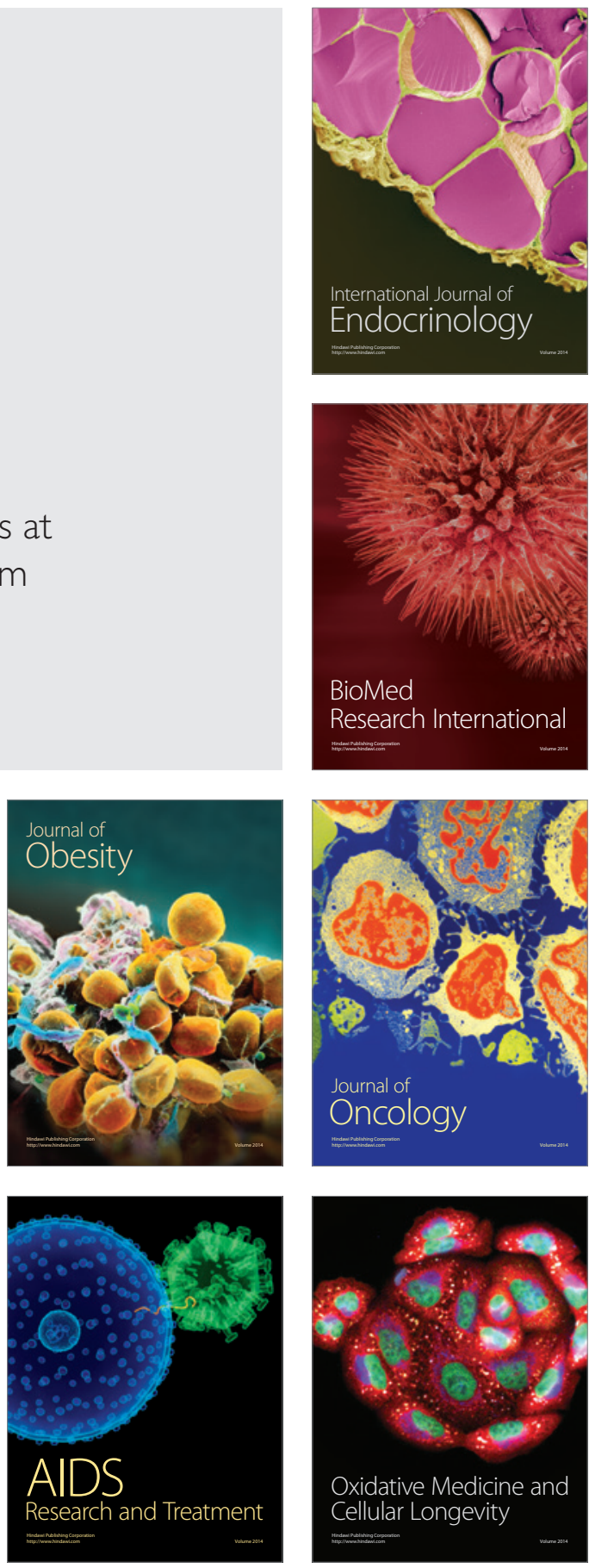